\title{
Comprehensive Investigation and Analysis of Bulk-heterojunction Microstructure of High-performance PCE11:PCBM Solar Cells
}

Chaohong Zhang ${ }^{\mathrm{a}, \mathrm{b}} *$, Thomas Heumueller ${ }^{\mathrm{b}}$, Wolfgang Gruber ${ }^{\mathrm{c}}$, Osbel Almora ${ }^{\mathrm{b}}$, Xiaoyan Du ${ }^{\mathrm{b}}$, Lei Ying ${ }^{\mathrm{d}}$, Junwu Chen ${ }^{\mathrm{d}}$, Tobias Unruh ${ }^{\mathrm{c}}$, Yong Cao ${ }^{\mathrm{d}}$, Ning $\mathrm{Li}^{\mathrm{b}, \mathrm{e}}$ *, Christoph J. Brabec ${ }^{\mathrm{b}, \mathrm{f}}$ *

a SUSTech Academy for Advanced Interdisciplinary Studies, Southern University of Science and Technology, No. 1088,xueyuan Rd., 518055, Shenzhen, Guangdong, P.R. China

${ }^{\mathrm{b}}$ Institute Materials for Electronics and Energy Technology (i-MEET), Friedrich-Alexander University Erlangen-Nürnberg, Martensstrasse 7, 91058 Erlangen, Germany

${ }^{c}$ Institute for Crystallography and Structure Physics, Friedrich-Alexander University Erlangen- Nürnberg, Staudtstrasse 3, 91058 Erlangen, Germany

${ }^{\mathrm{d}}$ Institute of Polymer Optoelectronic Materials and Devices, South China University of Technology, 381 Wushan Rd., 510640 Guangzhou, P.R. China

${ }^{\mathrm{e}}$ National Engineering Research Center for Advanced Polymer Processing Technology, Zhengzhou University, No.100 Science Avenue, 450002 Zhengzhou, China

${ }^{\mathrm{f}}$ Bavarian Center for Applied Energy Research (ZAE Bayern), Immerwahrstr. 2, 91058 Erlangen, Germany

*Author to whom correspondence should be addressed. E-mail: zhangch3@sustc.edu.cn; ning.li@fau.de; christoph.brabec@fau.de; 
Table S1. Molecular weight and polydispersity index (PDI) of studied PCE11

\begin{tabular}{lcc}
\hline Materials & $\mathbf{M}_{\mathbf{n}}$ & PDI \\
\hline PCE11-P0 & $96 \mathrm{k}$ & 1.8 \\
PCE11-P1 & $53 \mathrm{k}$ & 1.6 \\
PCE11-P2 & $43 \mathrm{k}$ & 2.1 \\
PCE11-P3 & $28 \mathrm{k}$ & 1.8 \\
PCE11-P4 & $6 \mathrm{k}$ & 1.2 \\
\hline
\end{tabular}

Table S2. Photovoltaic characteristics and processing parameters of PCE11:PCBM based organic solar cells

\begin{tabular}{|c|c|c|c|c|c|c|c|c|c|c|}
\hline Run & $\begin{array}{l}\text { Active } \\
\text { layer }\end{array}$ & $\begin{array}{c}\text { CB:oDCB } \\
\text { v/v } \\
\text { ratios }\end{array}$ & $\begin{array}{c}\text { Temperature }^{a} \\
\text { of solution } \\
\left({ }^{\circ} \mathrm{C}\right)\end{array}$ & $\begin{array}{c}\text { Pre- } \\
\text { annealing } \\
\text { Temp. }\left({ }^{\circ} \mathbf{C}\right) \text {, } \\
\text { time (min) }\end{array}$ & $\begin{array}{c}\text { Spin } \\
\text { coating } \\
\text { speed } \\
(\mathrm{rpm}) \\
\end{array}$ & $\begin{array}{l}\text { D:A } \\
\text { wt } \\
\text { ratios }\end{array}$ & $\begin{array}{c}J_{\mathrm{SC}}{ }^{b} \\
{\left[\mathrm{~mA} / \mathrm{cm}^{2}\right]}\end{array}$ & $\begin{array}{l}V_{\mathrm{OC}^{b}} \\
{[\mathrm{~V}]}\end{array}$ & $\begin{array}{l}\mathrm{FF}^{b} \\
{[\%]}\end{array}$ & $\begin{array}{l}\mathrm{PCE}^{b} \\
{[\%]}\end{array}$ \\
\hline 01 & P0:PCBM & $5: 5$ & 85 & - & 1000 & $1: 1.5$ & $13.1 \pm 2.4$ & $0.70 \pm 0.01$ & $41 \pm 0.02$ & $3.9 \pm 0.9$ \\
\hline 02 & & & 90 & - & 1000 & & $18.2 \pm 1.4$ & $0.76 \pm 0.01$ & $60 \pm 0.02$ & $8.4 \pm 0.4$ \\
\hline 03 & & & 95 & 95,2 & 1000 & & $16.9 \pm 0.7$ & $0.77 \pm 0.01$ & $63 \pm 0.02$ & $8.3 \pm 0.4$ \\
\hline 04 & & & 95 & - & 1000 & & $17.7 \pm 2.4$ & $0.72 \pm 0.01$ & $65 \pm 0.06$ & $8.7 \pm 1.5$ \\
\hline 05 & & & 100 & - & 1000 & & $17.7 \pm 0.7$ & $0.73 \pm 0.01$ & $69 \pm 0.01$ & $8.9 \pm 0.5$ \\
\hline 06 & & & 105 & - & 1000 & & $17.7 \pm 0.5$ & $0.73 \pm 0.01$ & $64 \pm 0.05$ & $8.2 \pm 0.6$ \\
\hline 1 & P1:PCBM & $5: 5$ & 90 & 90,3 & 1100 & $1: 1.5$ & $17.7 \pm 0.8$ & $0.76 \pm 0.01$ & $63 \pm 0.01$ & $8.4 \pm 0.4$ \\
\hline 2 & & & 90 & - & 1100 & & $19.2 \pm 0.7$ & $0.74 \pm 0.01$ & $65 \pm 0.01$ & $9.2 \pm 0.4$ \\
\hline 3 & & & 100 & 100,3 & 1100 & & $16.3 \pm 1.0$ & $0.78 \pm 0.01$ & $65 \pm 0.01$ & $8.2 \pm 0.4$ \\
\hline 4 & & & 100 & - & 1100 & & $17.5 \pm 1.9$ & $0.74 \pm 0.01$ & $68 \pm 0.01$ & $8.7 \pm 0.9$ \\
\hline 5 & & & 110 & 110,3 & 1100 & & $15.7 \pm 1.3$ & $0.78 \pm 0.01$ & $66 \pm 0.01$ & $8.0 \pm 0.6$ \\
\hline 6 & & & 110 & - & 1100 & & $16.2 \pm 0.3$ & $0.74 \pm 0.01$ & $67 \pm 0.01$ & $8.0 \pm 0.2$ \\
\hline 7 & & & 110 & - & 800 & & $17.7 \pm 1.2$ & $0.74 \pm 0.01$ & $66 \pm 0.01$ & $8.7 \pm 0.5$ \\
\hline 8 & P2:PCBM & $6: 4$ & 70 & - & 800 & $1: 1.2$ & $16.9 \pm 0.4$ & $0.75 \pm 0.01$ & $66 \pm 0.01$ & $8.4 \pm 0.4$ \\
\hline 9 & & & 80 & 80,5 & 800 & & $17.0 \pm 0.8$ & $0.78 \pm 0.01$ & $62 \pm 0.01$ & $8.2 \pm 0.4$ \\
\hline 10 & & & 80 & - & 800 & & $17.6 \pm 0.3$ & $0.75 \pm 0.01$ & $66 \pm 0.01$ & $8.7 \pm 0.1$ \\
\hline 11 & & & 80 & - & 700 & & $17.5 \pm 0.7$ & $0.74 \pm 0.01$ & $66 \pm 0.01$ & $8.6 \pm 0.3$ \\
\hline 12 & & & 90 & - & 800 & & $18.0 \pm 1.7$ & $0.75 \pm 0.01$ & $67 \pm 0.01$ & $9.0 \pm 0.8$ \\
\hline 13 & & & 70 & - & 800 & $1: 1.5$ & $18.1 \pm 0.5$ & $0.74 \pm 0.01$ & $67 \pm 0.01$ & $8.9 \pm 0.7$ \\
\hline 14 & & & 80 & 80,5 & 800 & & $17.6 \pm 0.6$ & $0.76 \pm 0.01$ & $65 \pm 0.01$ & $8.7 \pm 0.4$ \\
\hline 15 & & & 80 & - & 800 & & $17.8 \pm 2.4$ & $0.75 \pm 0.01$ & $65 \pm 0.01$ & $8.2 \pm 0.5$ \\
\hline 16 & & & 80 & - & 700 & & $18.3 \pm 2.4$ & $0.74 \pm 0.01$ & $64 \pm 0.01$ & $8.6 \pm 0.8$ \\
\hline 17 & & & 90 & - & 800 & & $17.6 \pm 0.5$ & $0.74 \pm 0.01$ & $62 \pm 0.01$ & $8.2 \pm 0.2$ \\
\hline 18 & P3:PCBM & $6: 4$ & 75 & - & 800 & $1: 1.5$ & $18.2 \pm 0.7$ & $0.75 \pm 0.01$ & $66 \pm 0.01$ & $8.9 \pm 0.4$ \\
\hline 19 & & & 80 & - & 800 & & $18.6 \pm 0.7$ & $0.75 \pm 0.01$ & $63 \pm 0.01$ & $8.8 \pm 0.5$ \\
\hline 20 & & & 85 & - & 800 & & $17.4 \pm 3.8$ & $0.76 \pm 0.01$ & $62 \pm 0.01$ & $8.2 \pm 1.0$ \\
\hline 21 & & & 90 & - & 800 & & $18.4 \pm 3.3$ & $0.75 \pm 0.01$ & $61 \pm 0.01$ & $8.4 \pm 1.1$ \\
\hline 22 & & & 95 & - & 800 & & $17.5 \pm 0.4$ & $0.75 \pm 0.01$ & $66 \pm 0.01$ & $8.3 \pm 0.4$ \\
\hline 23 & P4:PCBM & $6: 4$ & 40 & - & 800 & $1: 1.5$ & $4.1 \pm 0.3$ & $0.81 \pm 0.02$ & $40 \pm 0.05$ & $1.3 \pm 0.2$ \\
\hline 24 & & & 50 & - & 800 & & $5.0 \pm 0.2$ & $0.82 \pm 0.04$ & $52 \pm 0.1$ & $2.2 \pm 0.2$ \\
\hline 25 & & & 60 & - & 800 & & $4.7 \pm 0.3$ & $0.83 \pm 0.01$ & $56 \pm 0.03$ & $2.2 \pm 0.1$ \\
\hline 26 & & & 70 & - & 800 & & $5.4 \pm 0.3$ & $0.83 \pm 0.01$ & $58 \pm 0.01$ & $2.6 \pm 0.2$ \\
\hline 27 & & & 75 & - & 800 & & $3.7 \pm 0.9$ & $0.82 \pm 0.01$ & $55 \pm 0.02$ & $1.7 \pm 0.5$ \\
\hline
\end{tabular}

$a$ : the ITO substrates were pre-heated at the same temperature of solution for 2 minutes; ${ }^{b}$ : average of 6 devices. 
For better comparison, solar cells from the same batch of PCE11 under various processing conditions were fabricated in one run, i.e. Run $01 \sim 06$ were fabricated in the same run.
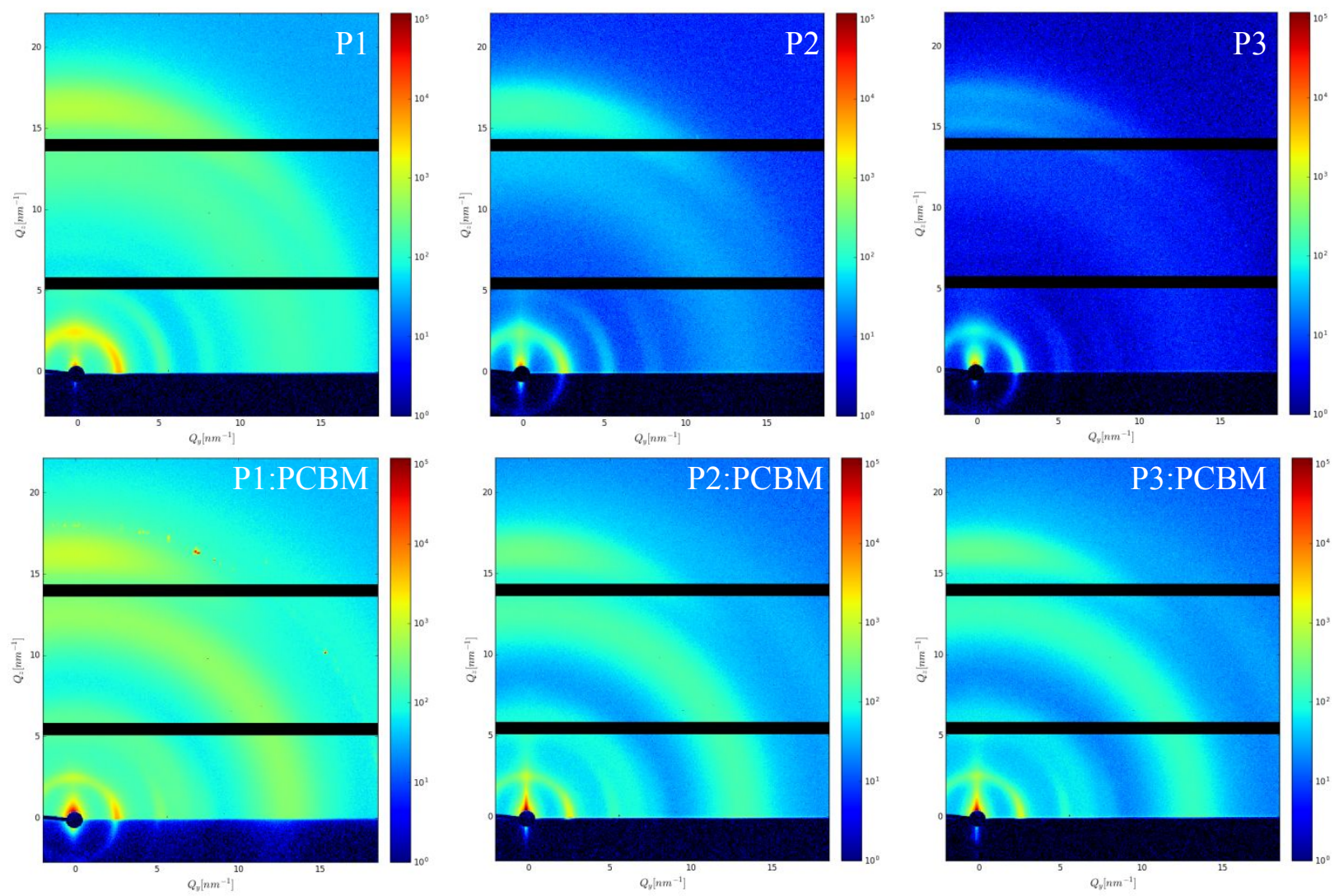

Figure S1. 2D GIWAXS patterns of polymers in pristine and in blends. The film thickness of the samples are P1: 880 nm, P2: 169 nm, P3: 299 nm, P1-PCBM: 1345 nm, P2-PCBM: 248 nm, P3-PCBM: 282 nm; the measured time of $\mathrm{P} 3$ is five minutes each spot while the measured time of other samples is 10 minutes each spot. The linecuts of the samples are corrected with sample thickness and measured time. 

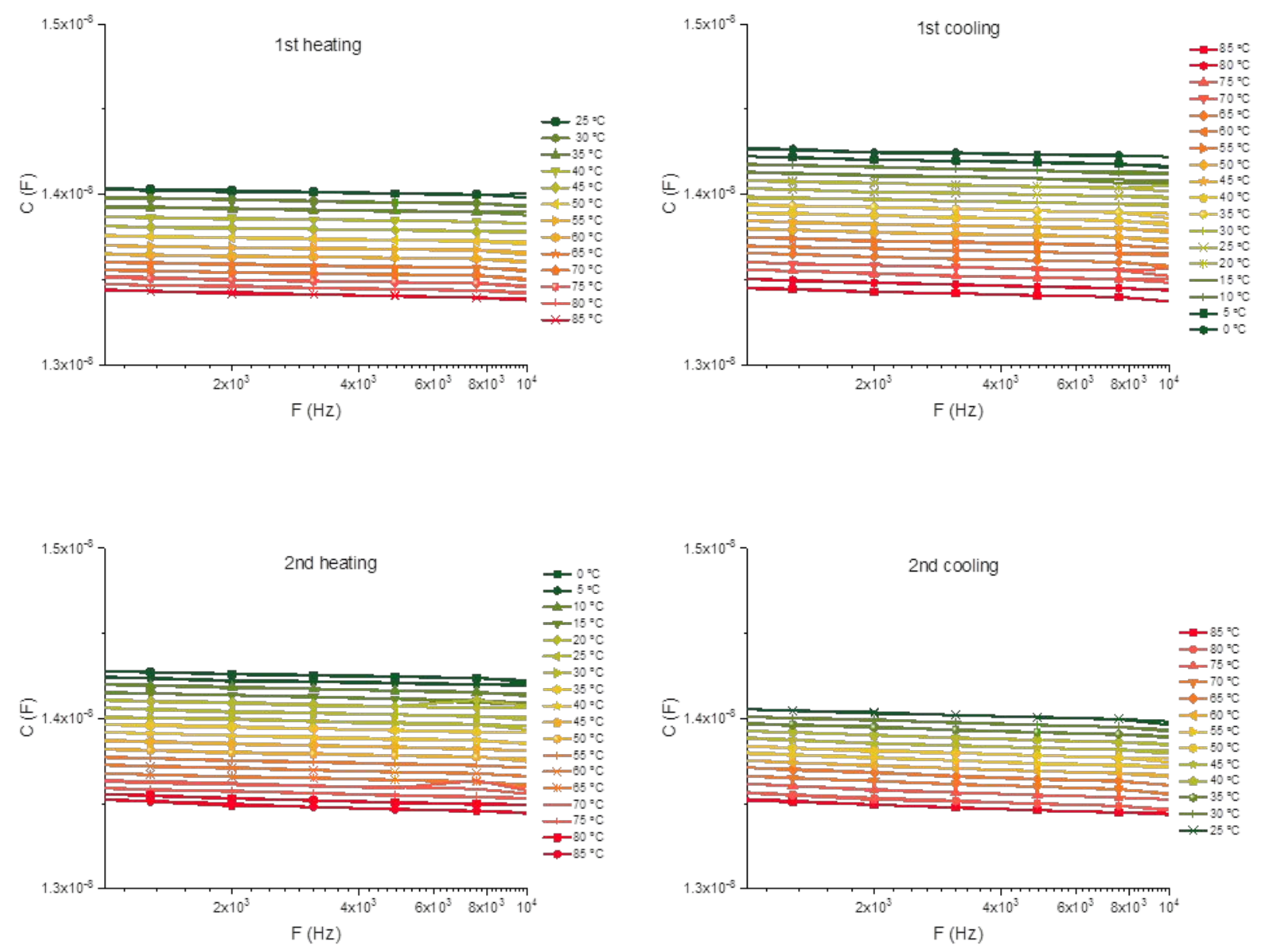

Figure S2. Capacitance as a function of frequency of P1 during $1^{\text {st }}$ and $2^{\text {nd }}$ heating/cooling scans. 

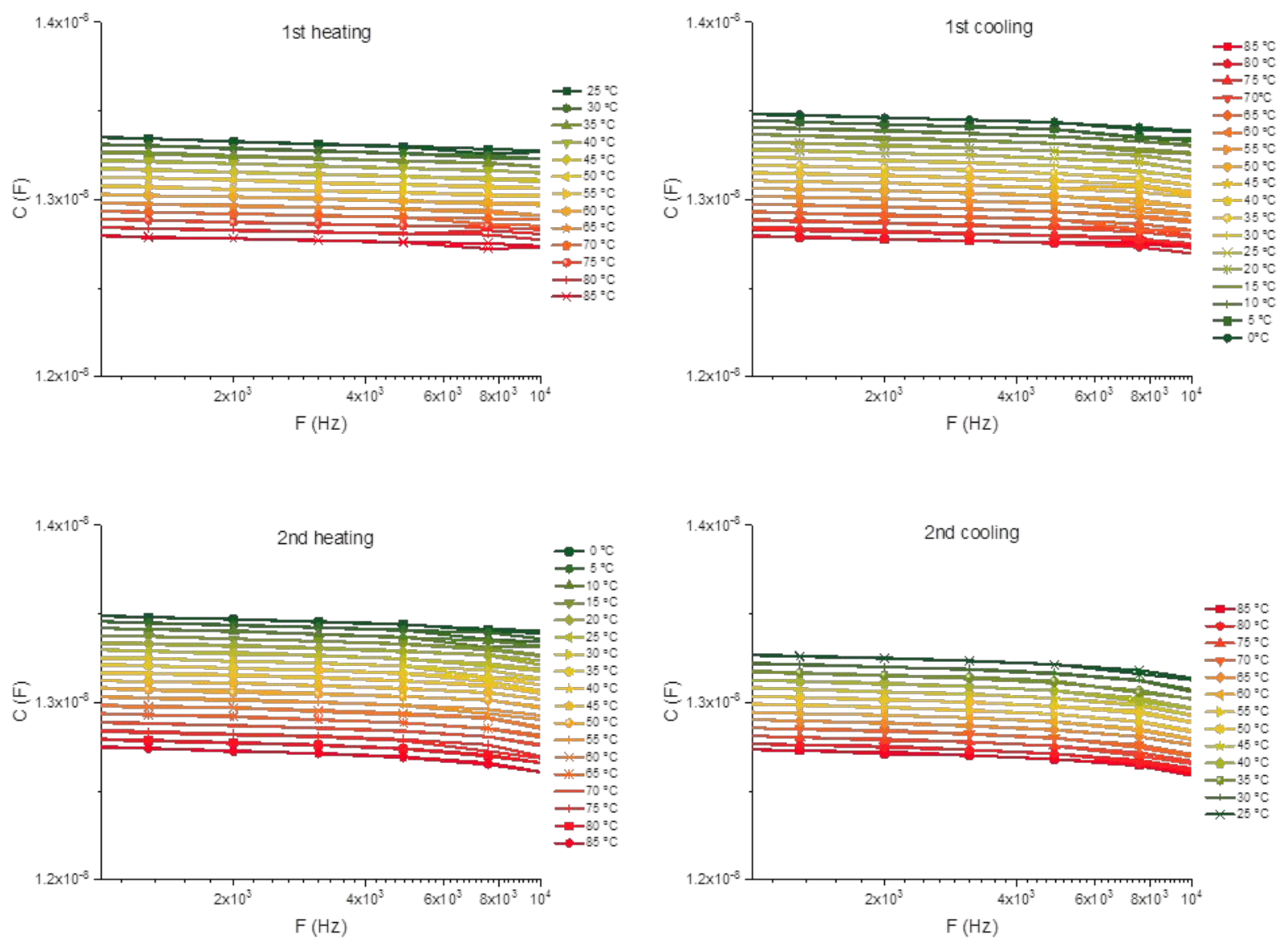

Figure S3. Capacitance as a function of frequency of P2 during $1^{\text {st }}$ and $2^{\text {nd }}$ heating/cooling scans. 

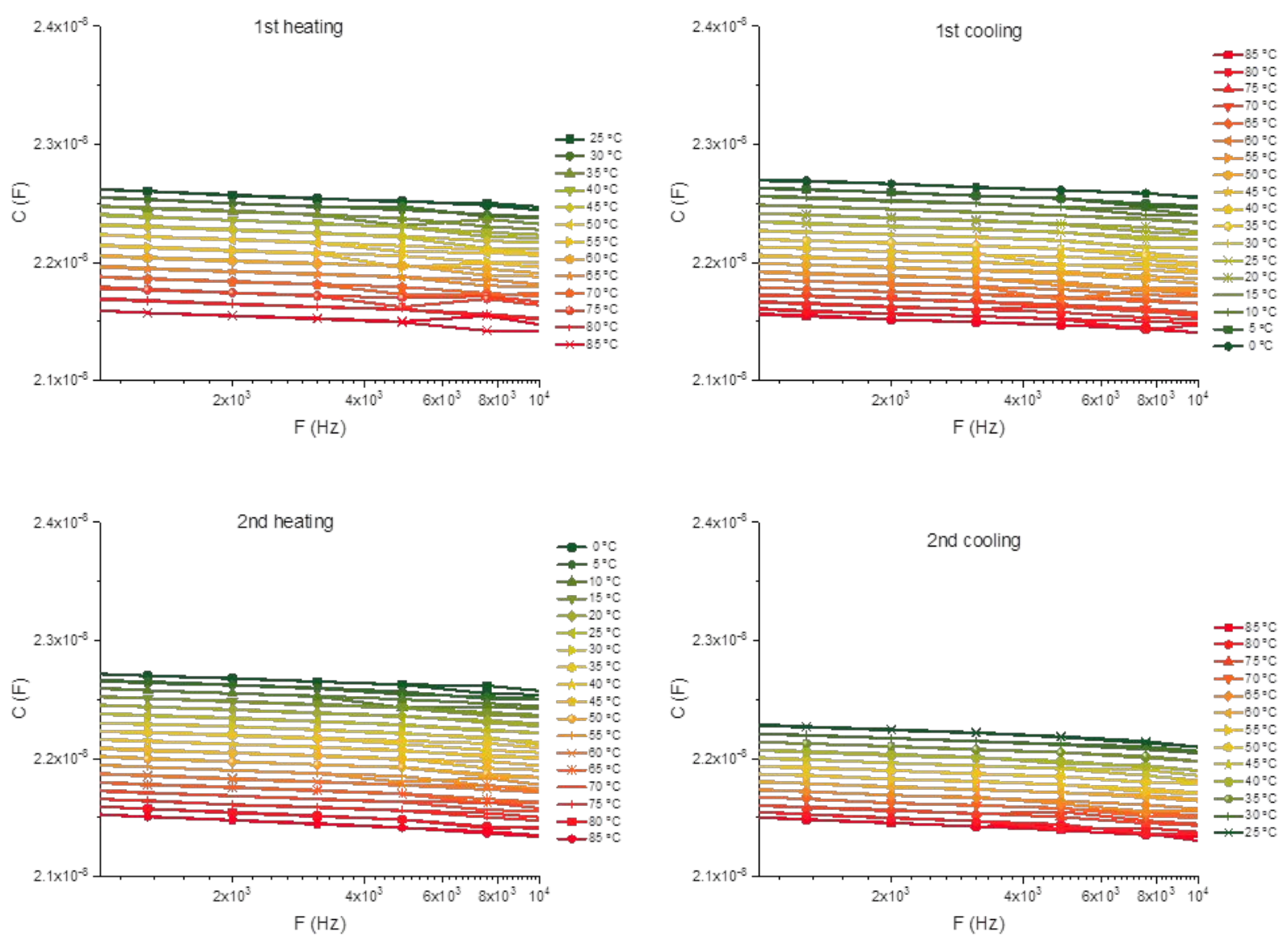

Figure S4. Capacitance as a function of frequency of P3 during $1^{\text {st }}$ and $2^{\text {nd }}$ heating/cooling scans. 

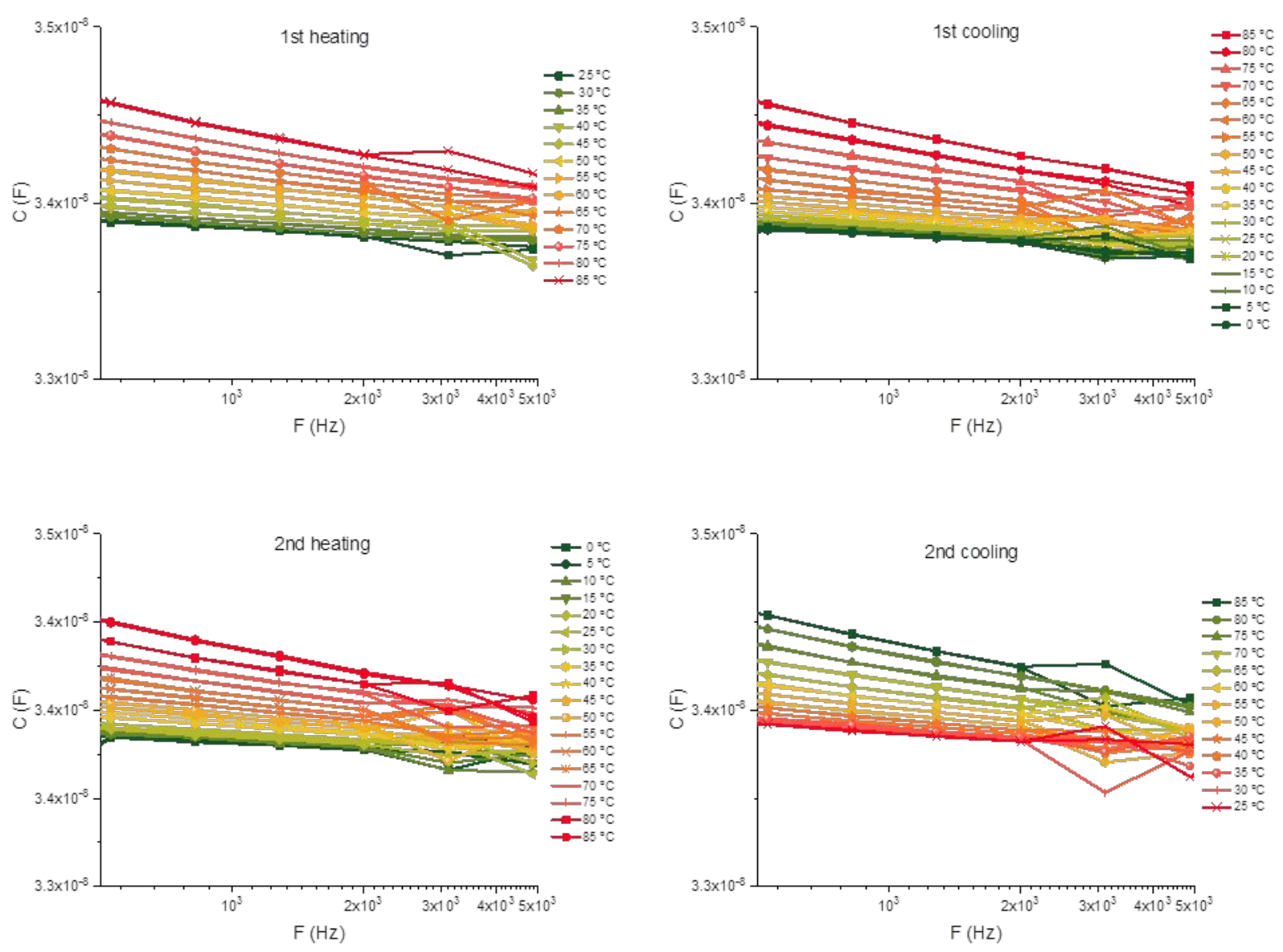

Figure S5. Capacitance as a function of frequency of PCBM during $1^{\text {st }}$ and $2^{\text {nd }}$ heating/cooling scans.
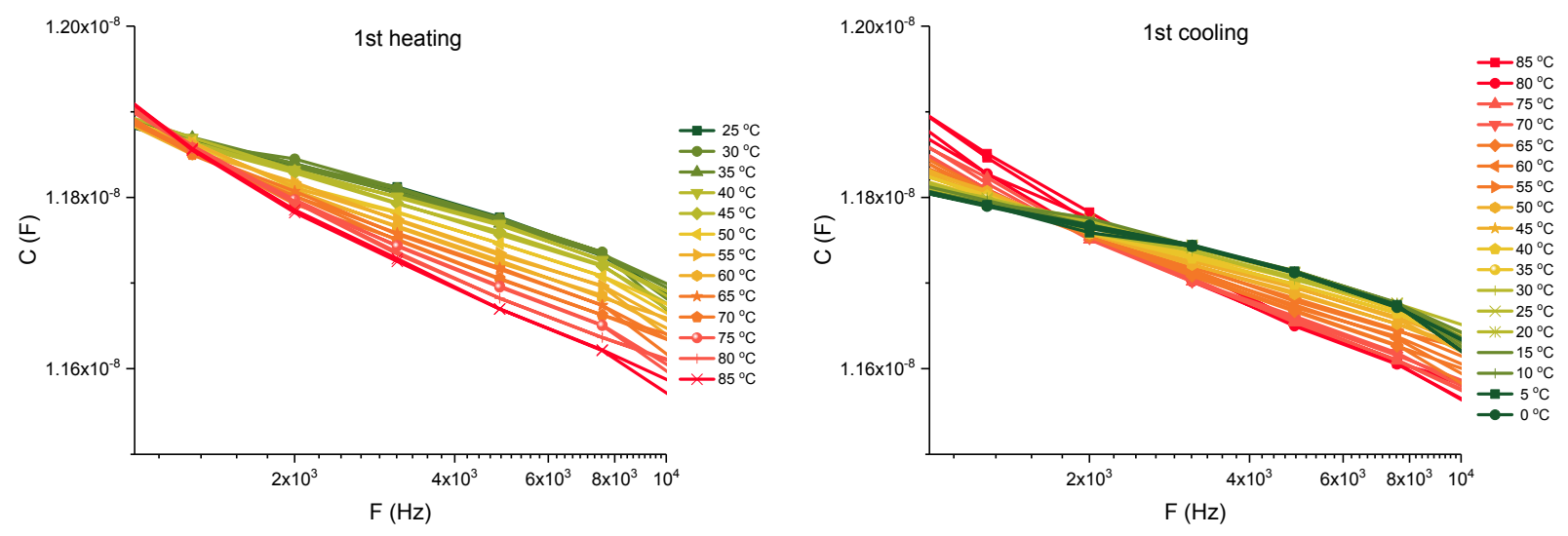

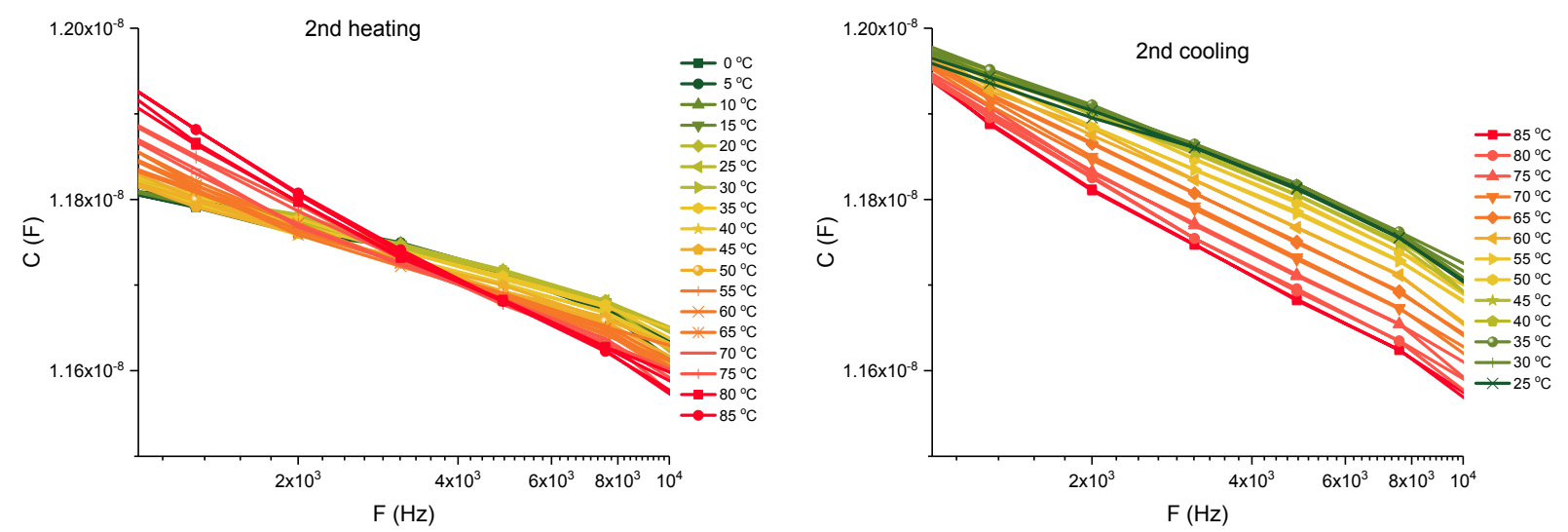

Figure S6. Capacitance as a function of frequency of P1:PCBM blends during $1^{\text {st }}$ and $2^{\text {nd }}$ heating/cooling scans.
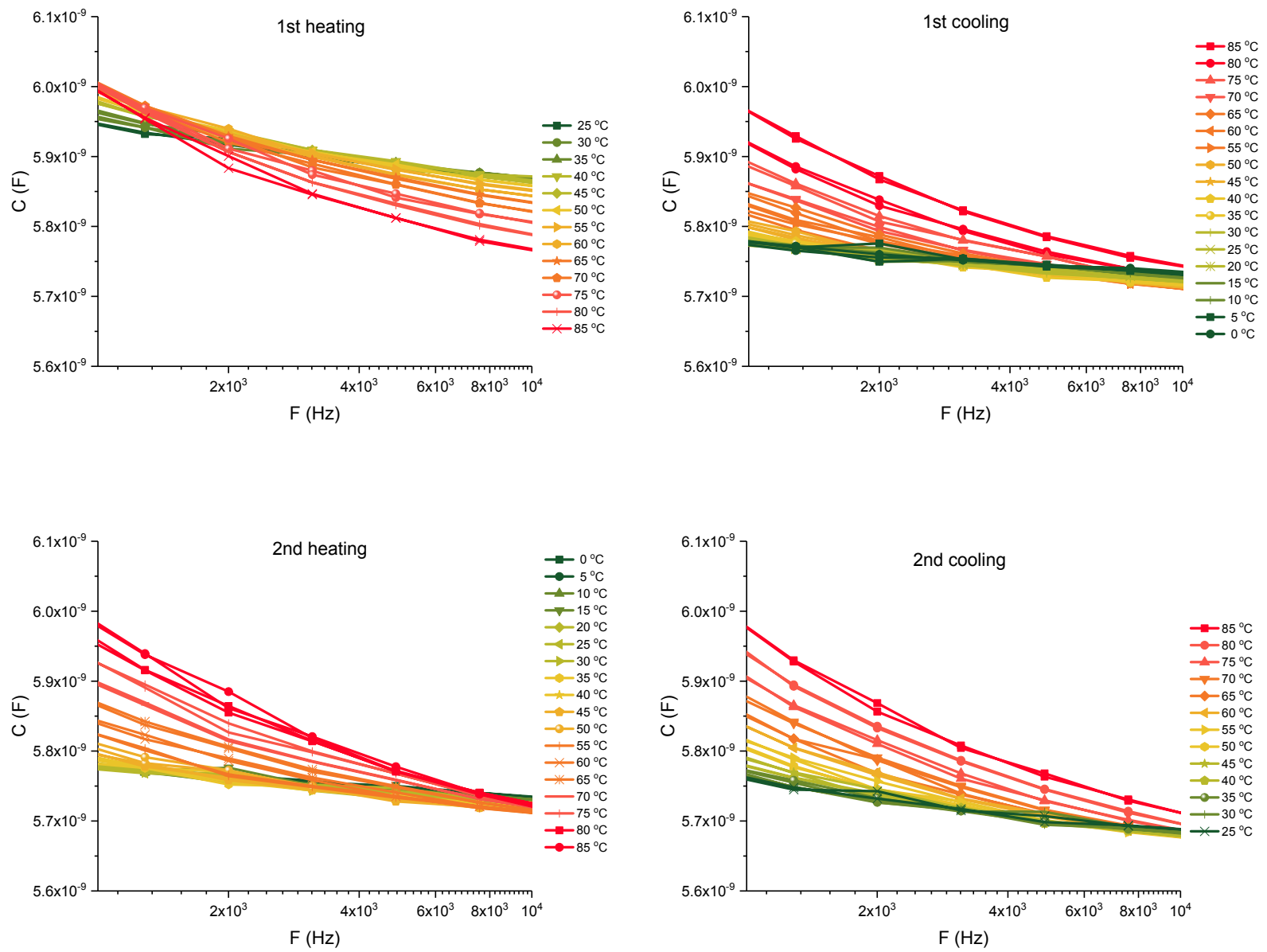

Figure S7. Capacitance as a function of frequency of P2:PCBM blends during $1^{\text {st }}$ and $2^{\text {nd }}$ heating/cooling scans. 

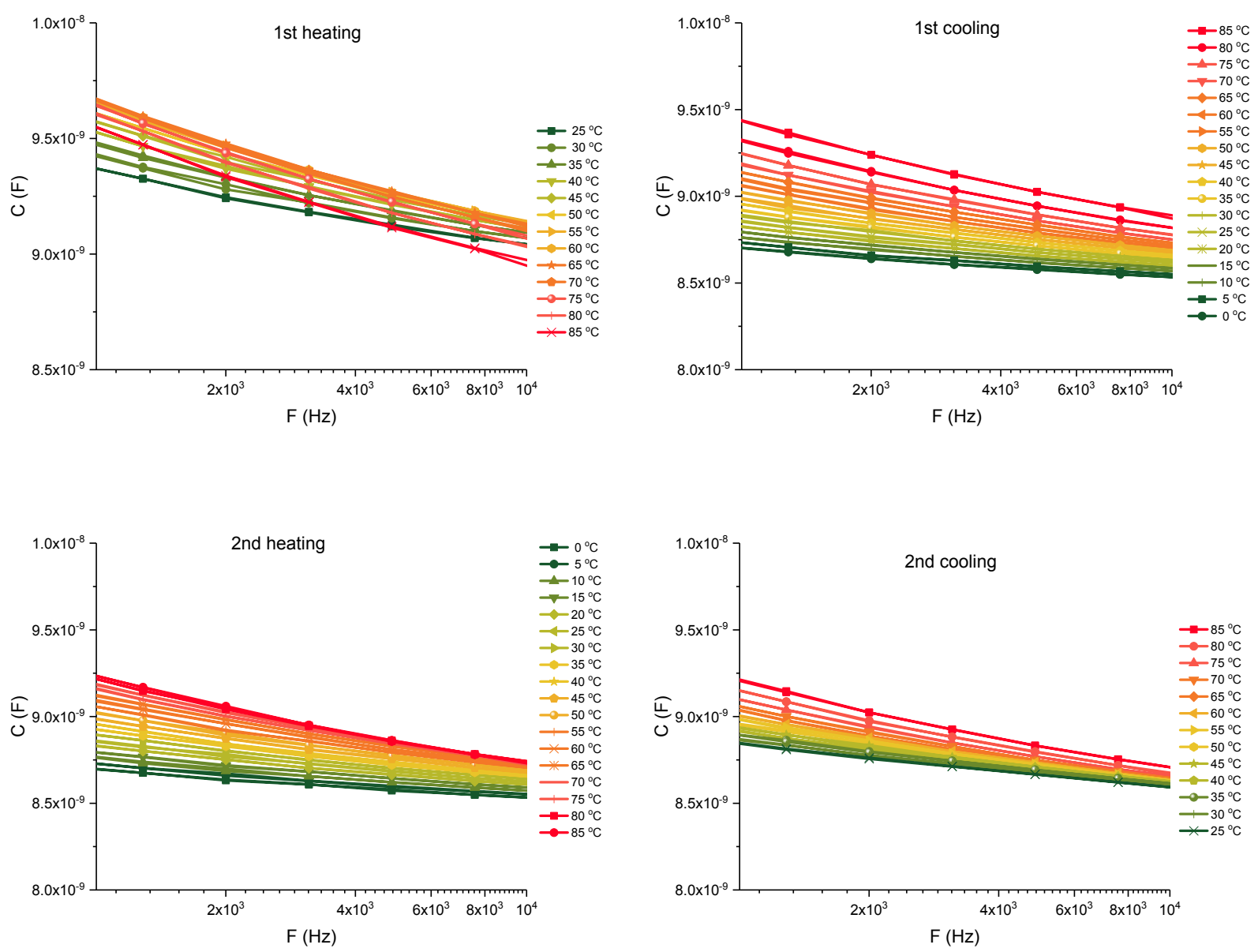

Figure S8. Capacitance as a function of frequency of P3:PCBM blends during $1^{\text {st }}$ and $2^{\text {nd }}$ heating/cooling scans.

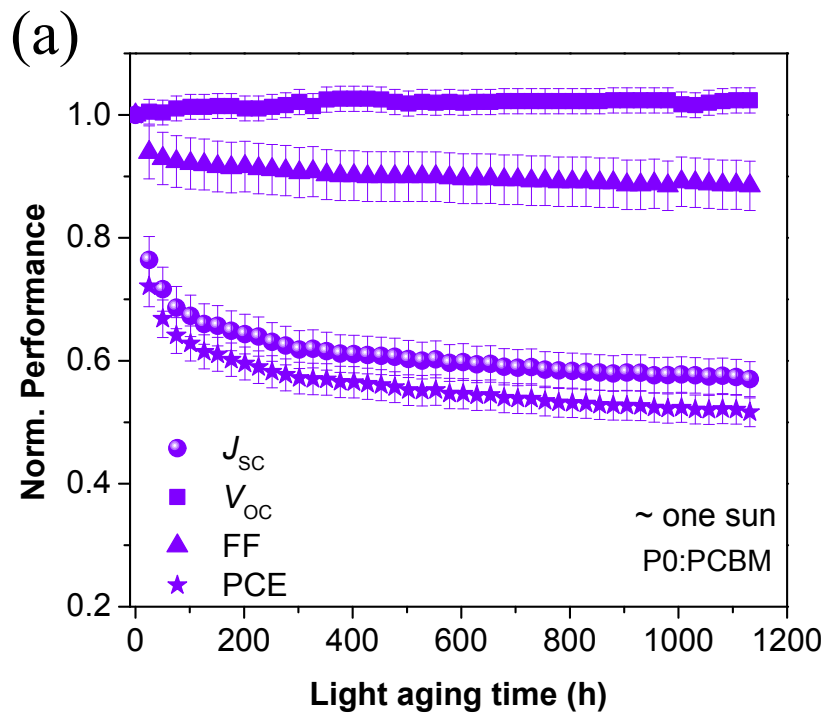

(b)

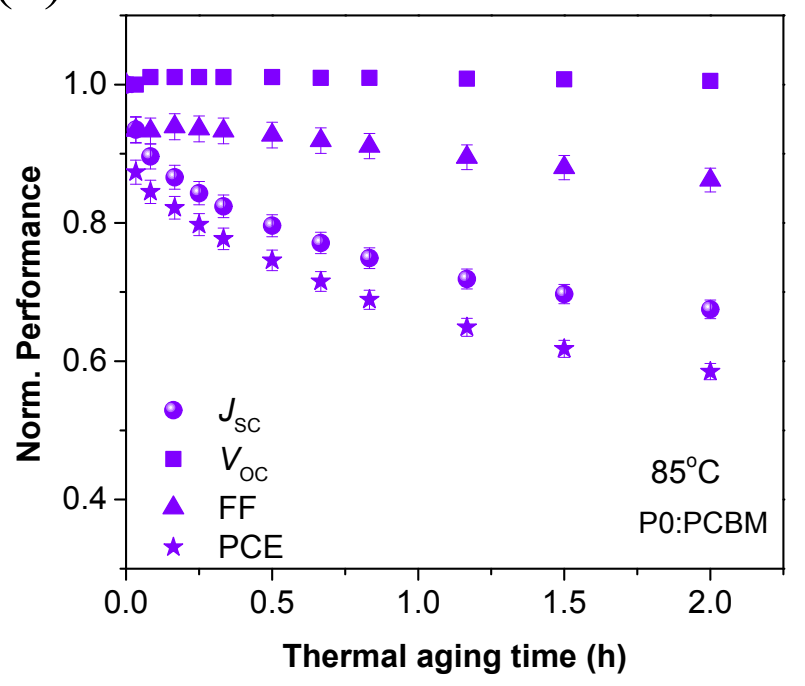


Figure S9. Normalized $J_{\mathrm{SC}}, V_{\mathrm{OC}}$, FF and PCE evolution of PCE11-P0:PCBM solar cells aged under white light illumination (a) and under thermal stress (b) in nitrogen atmosphere.
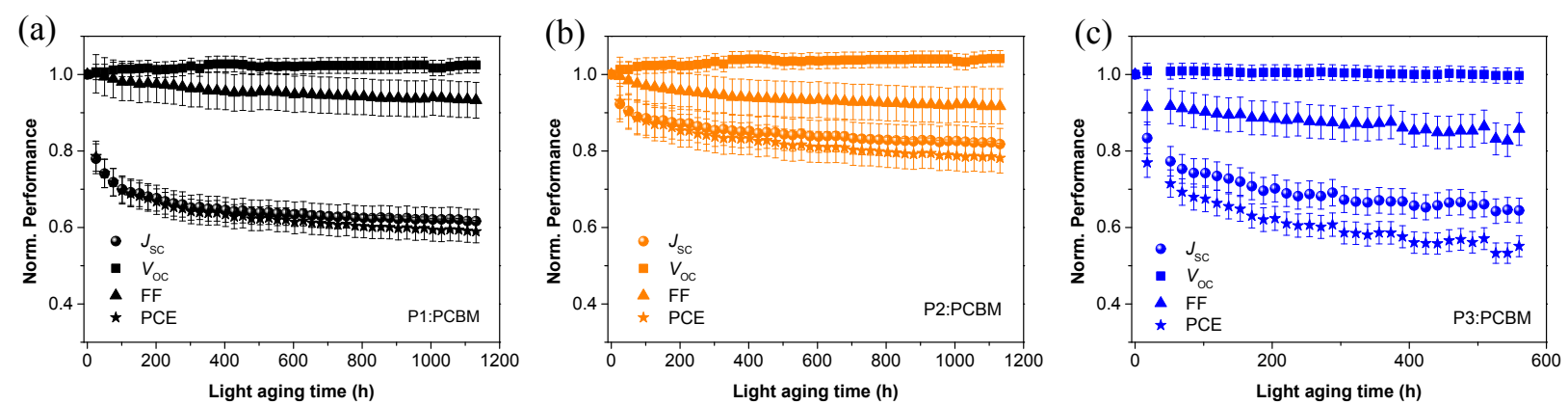

Figure S10. Normalized $J_{\mathrm{SC}}, V_{\mathrm{OC}}$, FF and PCE evolution of PCE11:PCBM solar cells aged under white light illumination in nitrogen atmosphere.
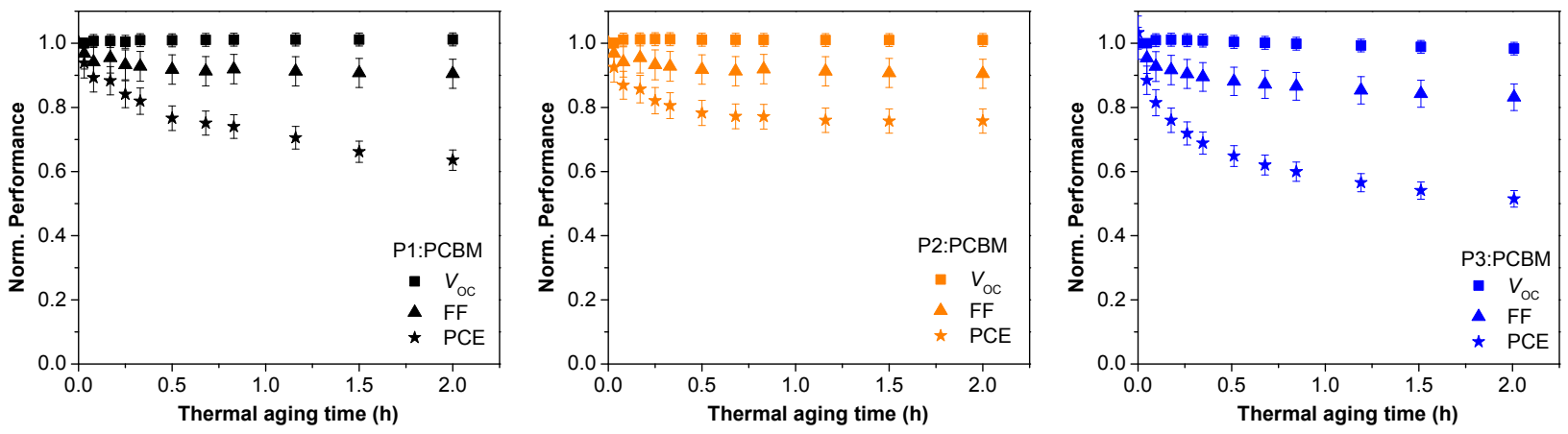

Figure S11. Normalized $V_{\mathrm{OC}}, \mathrm{FF}$ and PCE evolution of PCE11:PCBM solar cells aged at $85{ }^{\circ} \mathrm{C}$ in nitrogen atmosphere. 

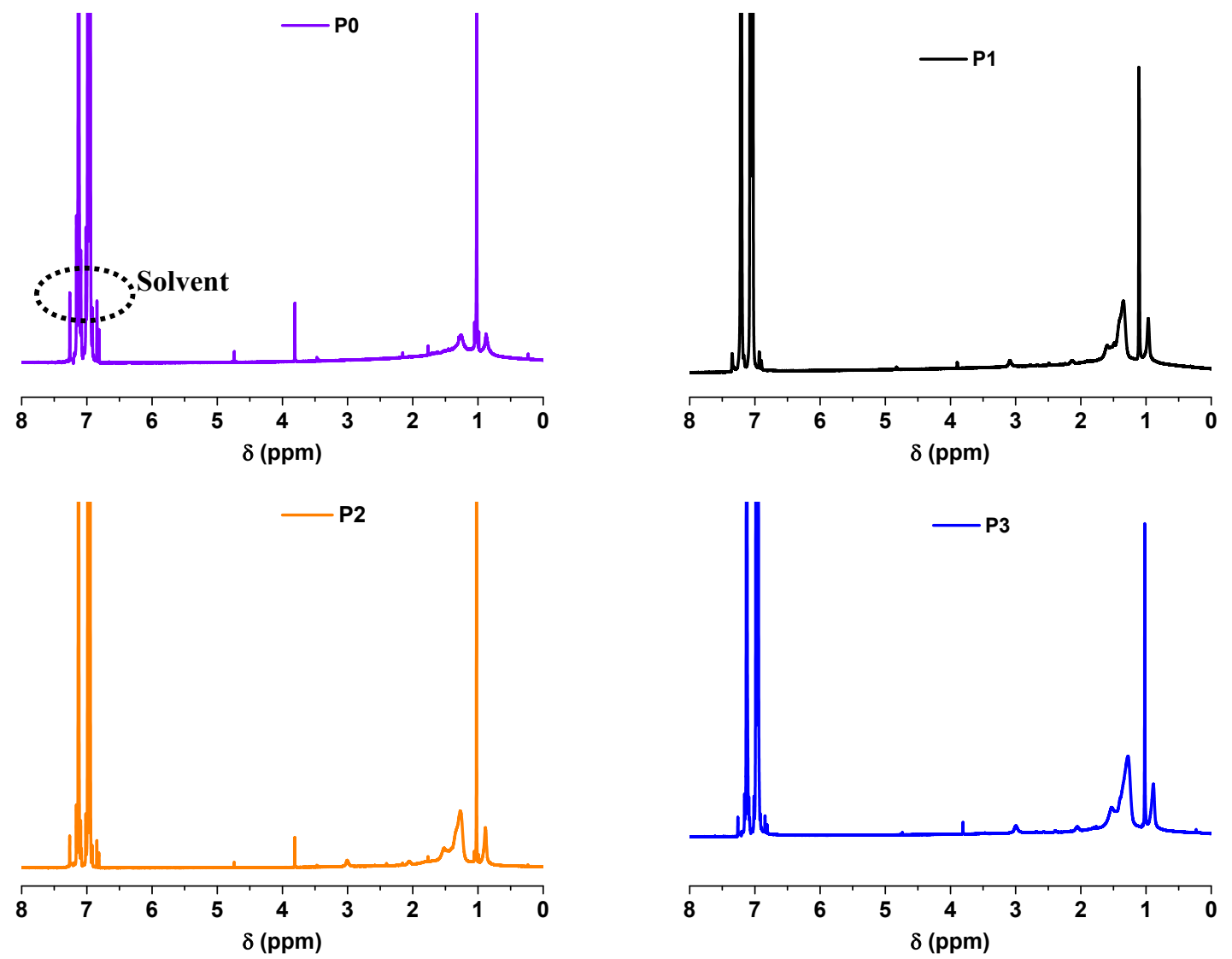

Figure S12. ${ }^{1} \mathrm{H}$ NMR spectra of $\mathrm{P} 0, \mathrm{P} 1, \mathrm{P} 2$, and $\mathrm{P} 3$ in $\mathrm{C}_{6} \mathrm{D}_{5} \mathrm{Cl} .{ }^{1} \mathrm{H}$ NMR features of $\mathrm{C}_{6} \mathrm{D}_{5} \mathrm{Cl}$ are 6.96, 6.99, and $7.14 \mathrm{ppm}^{1}$. 
(a)

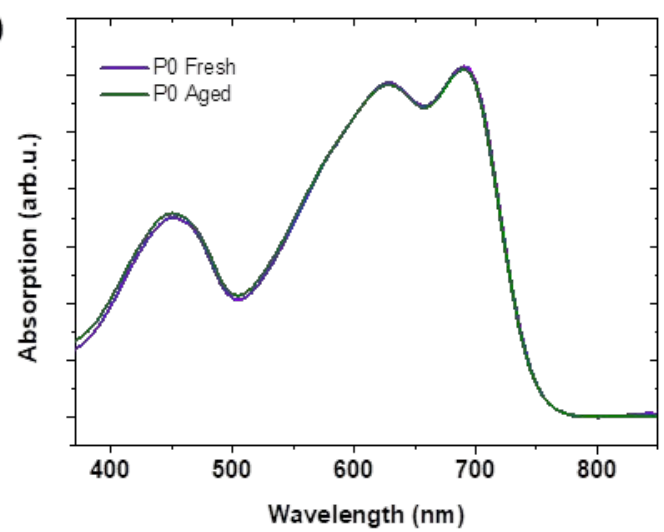

(c)

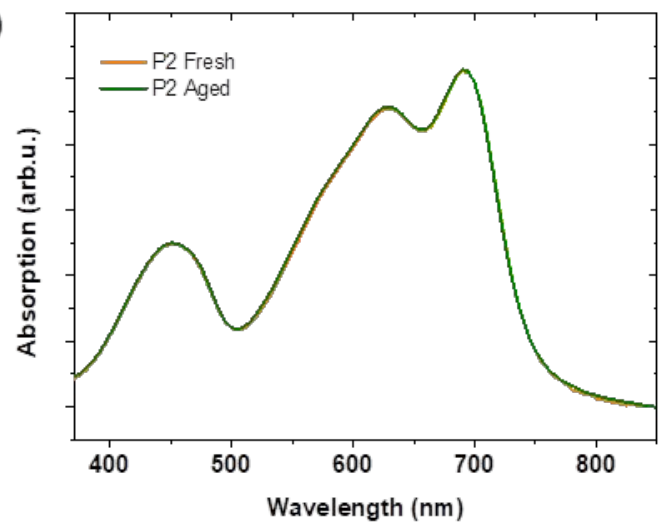

(b)

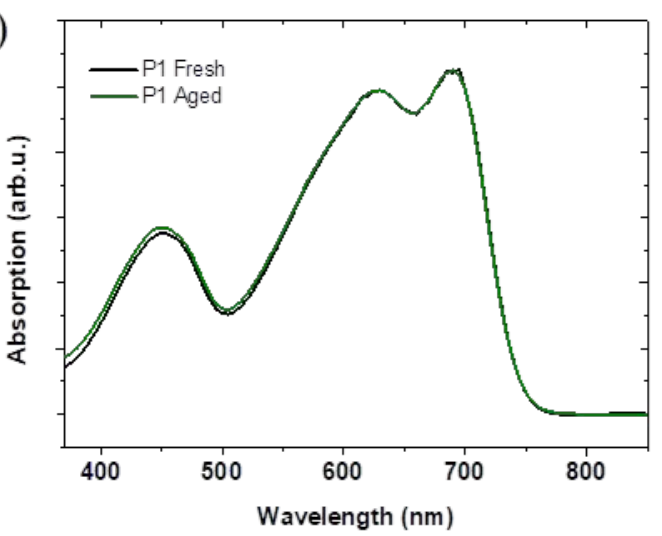

(d)

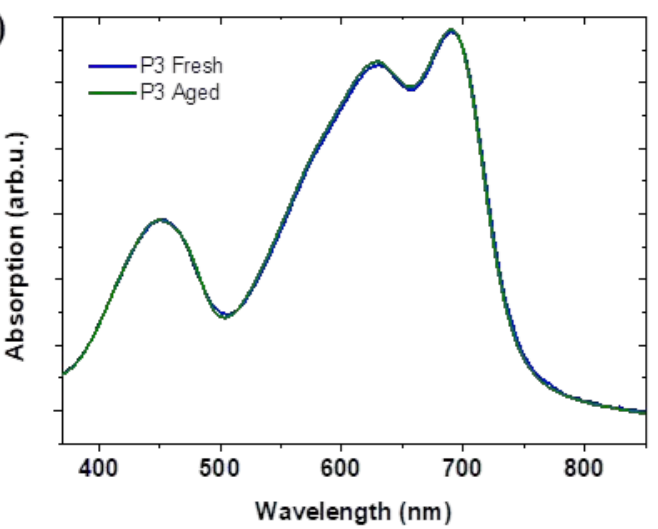

Figure S13. Absorption of P0, P1, P2, and P3 films before and after aging under white LED illumination.

(a)

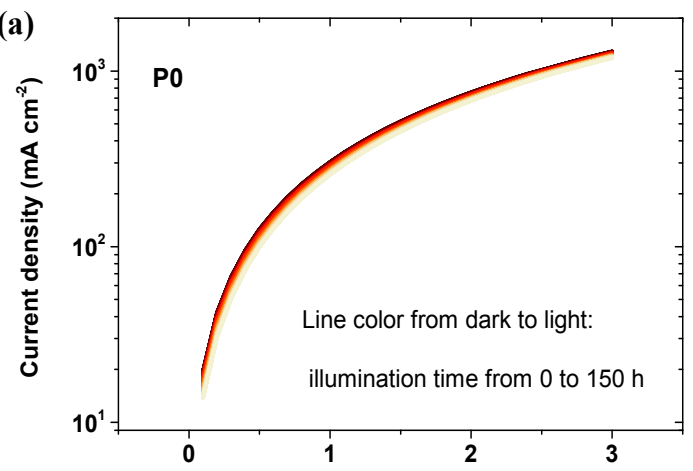

(c)

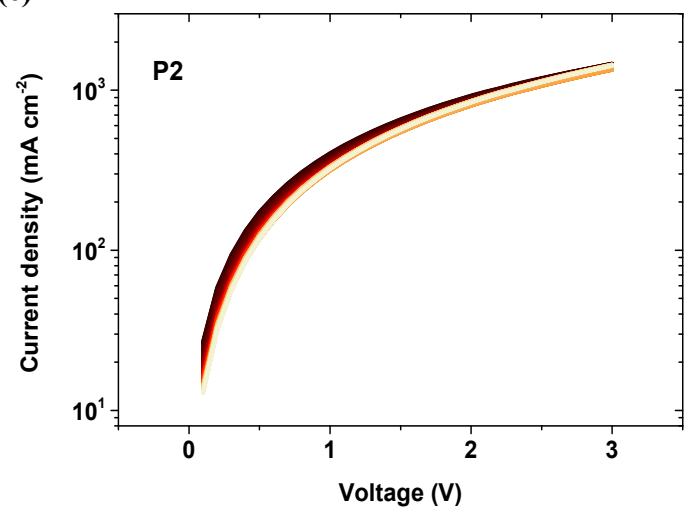

(b)

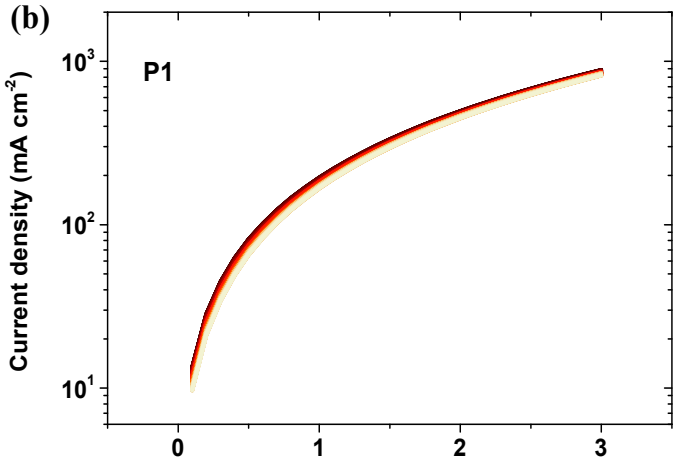

(d)

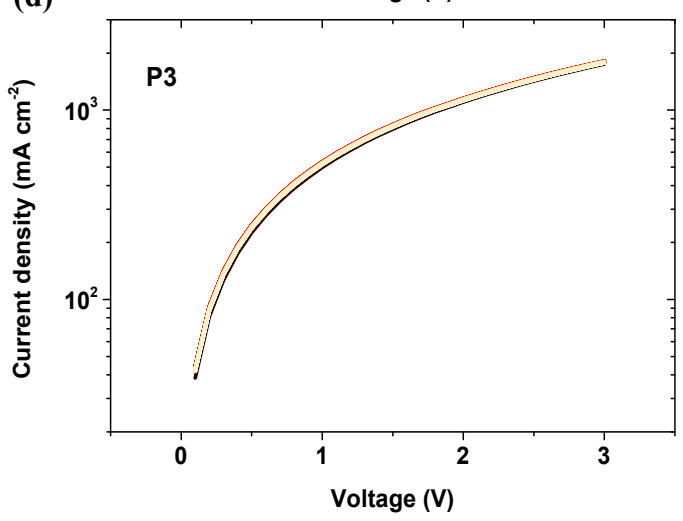


Figure S14. Stability of hole-only devices of P0, P1, P2, and P3 (structure: ITO/PEDOT:PSS/polymer/MoOx/Ag) under white LED for $150 \mathrm{~h}$.
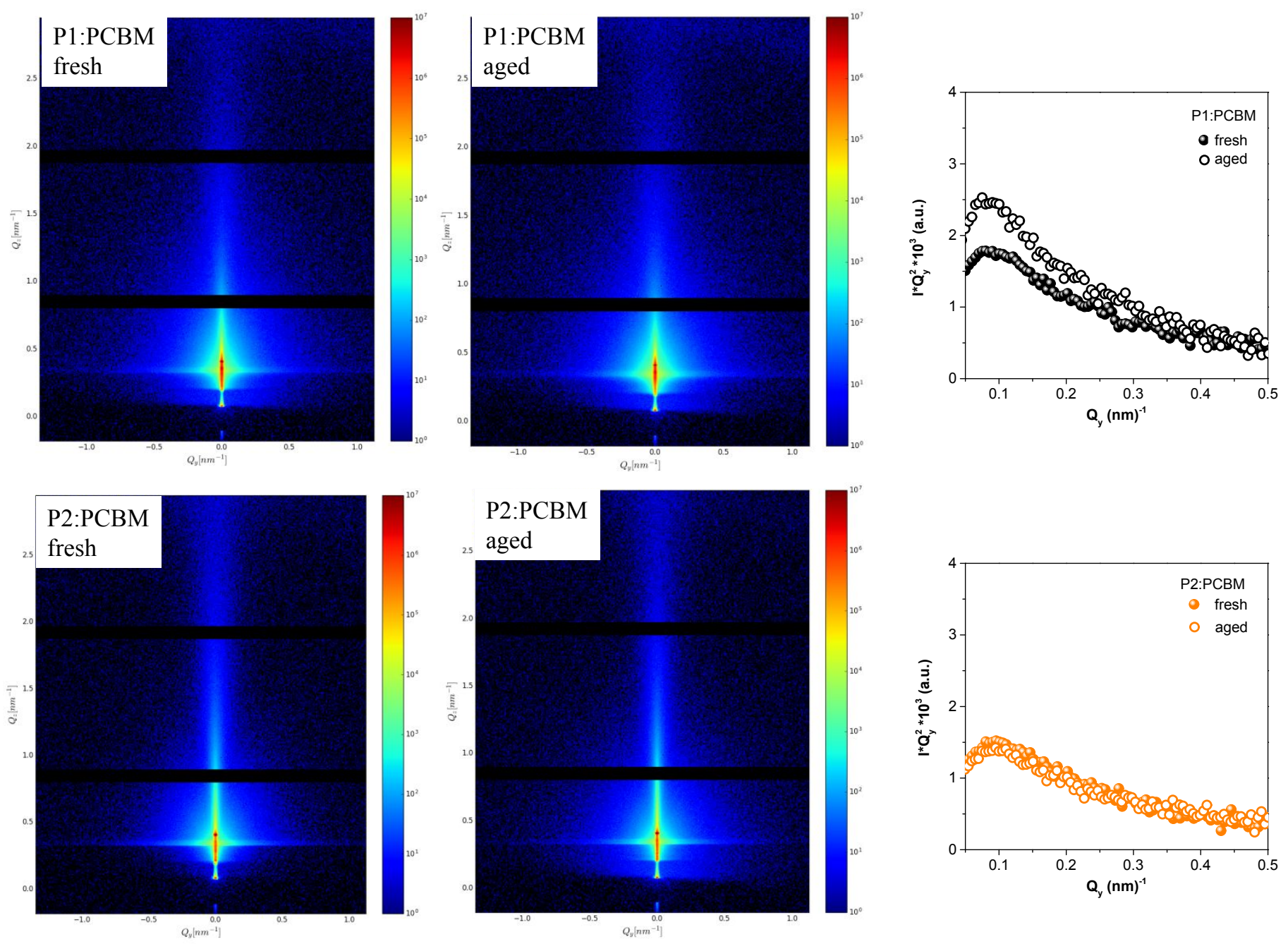

Figure S15. 2D and $\mathrm{Q}_{\mathrm{y}}$ line-cut profiles of P1:PCBM and P2:PCBM films before and after thermal aging.

\section{Reference}

(1) Fulmer, G. R.; Miller, A. J. M.; Sherden, N. H.; Gottlieb, H. E.; Nudelman, A.; Stoltz, B. M.; Bercaw, J. E.; Goldberg, K. I. NMR Chemical Shifts of Trace Impurities: Common Laboratory Solvents, Organics, and Gases in Deuterated Solvents Relevant to the Organometallic Chemist. Organometallics, 2010, 29, 2176-2179. 